\title{
A revision of Entobdella Blainville in Lamarck, 1818, with special emphasis on the nominal (type) species "Entobdella hippoglossi (Müller, 1776) Blainville, 1818" (Monogenea: Capsalidae: Entobdellinae) from teleost flatfishes, with descriptions of three new species and a new genus
}

\author{
GRAHAM C. KEARN ${ }^{1}$, IAN D. WHITTINGTON ${ }^{2,3} \&$ RICHARD EVANS-GOWING $^{1}$ \\ ${ }^{\prime}$ School of Biological Sciences, University of East Anglia, Norwich, NR4 7TJ, Norfolk, U.K. \\ E-mail:g.kearn@uea.ac.uk; r.evansgowing@uea.ac.uk \\ ${ }^{2}$ Monogenean Research Laboratory, Parasitology Section, The South Australian Museum, North Terrace, Adelaide, South Australia \\ 5000, Australia.E-mail: whittington.ian@saugov.sa.gov.au \\ ${ }^{3}$ Marine Parasitology Laboratory, School of Earth and Environmental Sciences (DX 650 418), The University of Adelaide, North Ter- \\ race, Adelaide, South Australia 5005, Australia
}

\section{Table of contents}

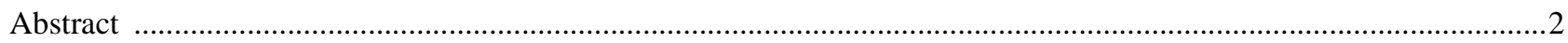

Introduction

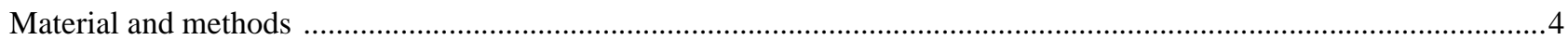

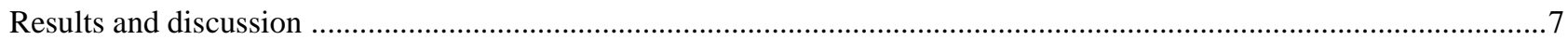

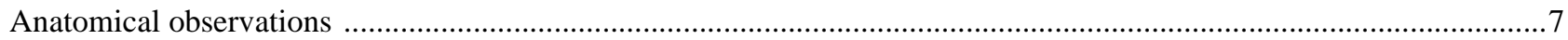

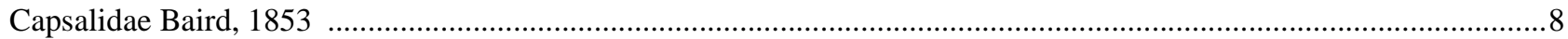

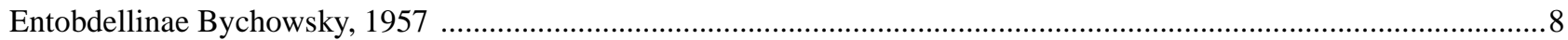

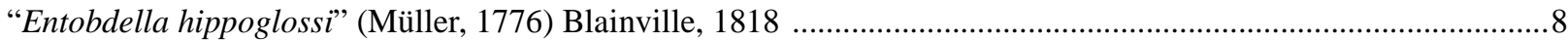

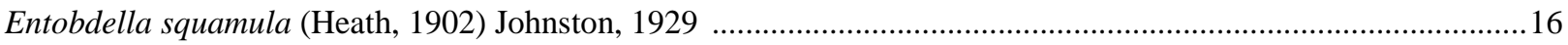

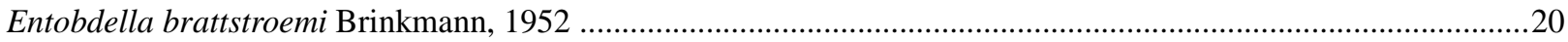

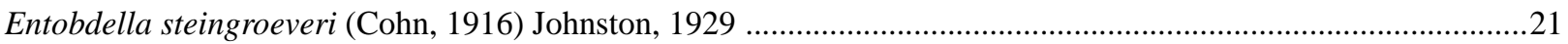

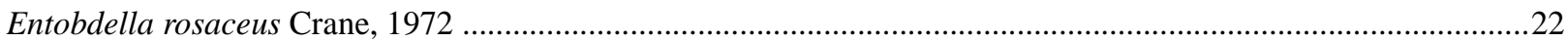

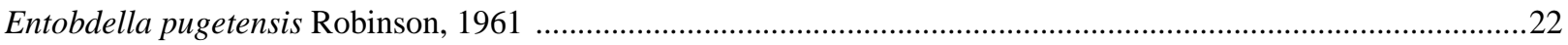

Entobdella soleae (Van Beneden \& Hesse, 1864) Johnston, 1929 ......................................................................22

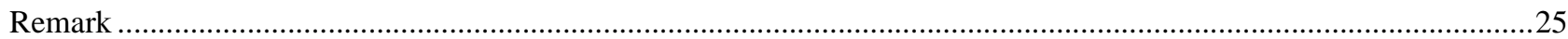

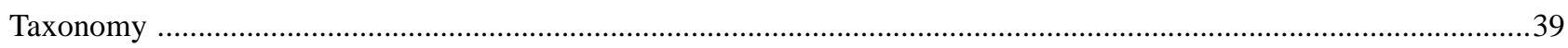

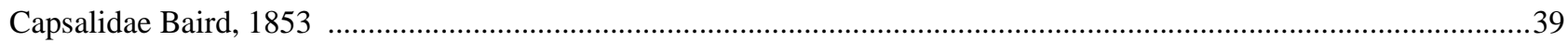

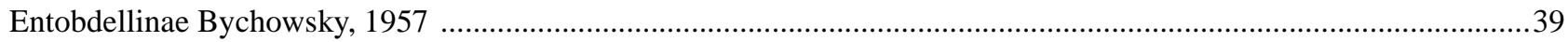

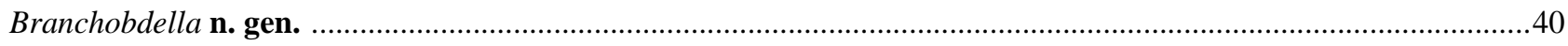

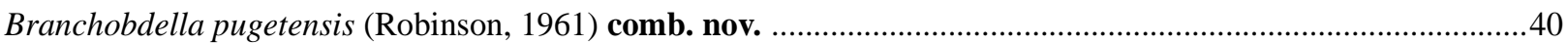

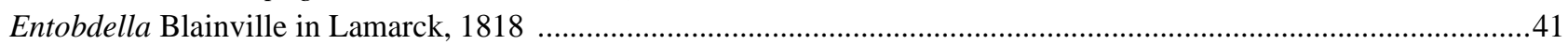

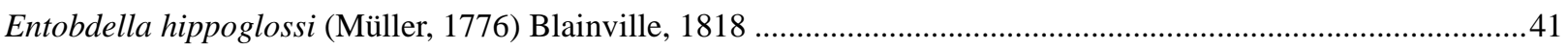

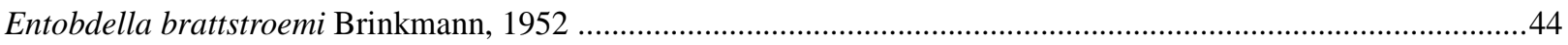

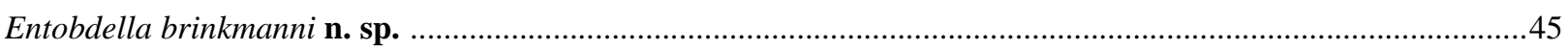

Entobdella soleae (Van Beneden \& Hesse, 1864) Johnston, 1929 ........................................................................46

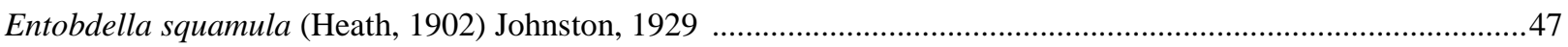

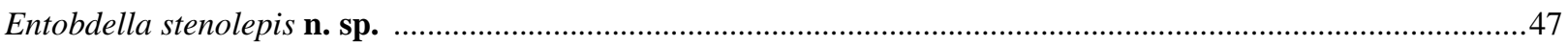

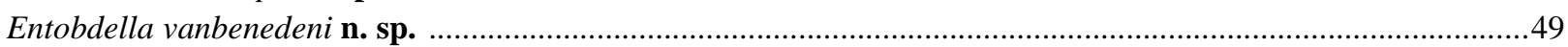

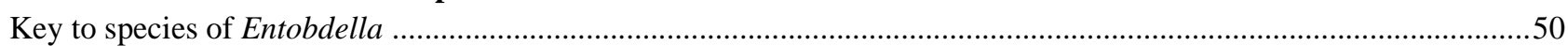

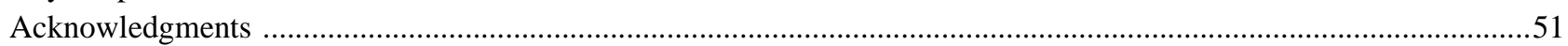

References 


\section{Abstract}

Species of Entobdella Blainville in Lamarck, 1818, from skin (less commonly gills) of teleost flatfishes and occasionally from round-bodied teleosts are reviewed, with special reference to the nominal (type) species "Entobdella hippoglossi (Müller, 1776) Blainville, 1818" (Monogenea: Capsalidae: Entobdellinae) and to E. pugetensis Robinson, 1961. In the late 20th century the following 5 species were synonymised with E. hippoglossi: E. brattstroemi Brinkmann, $1952 ;$ E. curvunca Ronald, 1957; E. rosaceus Crane, 1972; E. squamula (Heath, 1902) Johnston, 1929; E. steingroeveri (Cohn, 1916) Johnston, 1929. We have shown that E. brattstroemi and E. squamula are valid, E. curvunca is a synonym of $E$. hippoglossi and E. rosaceus and E. steingroeveri are species inquirendae. Specimens of E. steingroeveri, first described in 1916 by Cohn, have been re-examined. Parasites from the Pacific Ocean on Hippoglossus stenolepis Schmidt, 1904 (Pacific halibut) and Eopsetta jordani (Lockington, 1879) (Petrale sole) (Pleuronectiformes: Pleuronectidae) and parasites geographically isolated in the Atlantic Ocean on H. hippoglossus (Linnaeus, 1758) (Atlantic halibut) and Reinhardtius hippoglossoides (Walbaum, 1792) (Greenland halibut) (Pleuronectiformes: Pleuronectidae) have all been regarded as E. hippoglossi. We confirm that E. hippoglossi sensu stricto is a parasite of the Atlantic halibut, but is accompanied on the same host by a second entobdelline species, E. vanbenedeni n. sp. It differs from the type species, E. hippoglossi in the anatomy of the distal region of the vagina and in the number, distribution and shape of papillae on the ventral surface of the haptor. Parasites from H. stenolepis are morphologically similar to E. hippoglossi on H. hippoglossus (no second species has been found on $H$. stenolepis), but differences in the number and shapes of haptor papillae support proposal of the parasites from H. stenolepis as a distinct species, E. stenolepis n. sp. Our anatomical studies of these parasites, with the exception of $E$. pugetensis, have revealed a cluster of several seminal receptacles opening into the ovo-vitelline duct. Previous reports of a single seminal receptacle in E. stenolepis (as E. hippoglossi) and E. steingroeveri are erroneous. Furthermore, reports of the vagina opening proximally into the alleged single seminal receptacle are also incorrect; direct and indirect evidence suggests that in all these parasite species, including E. pugetensis, the vagina opens proximally into the vitelline reservoir. Entobdella squamula from Paralichthys californicus (Ayers, 1859) (California flounder) (Pleuronectiformes: Paralichthyidae) differs from E. stenolepis, E. hippoglossi and E. vanbenedeni in the relative lengths of the accessory sclerites and anterior hamuli. Parasites originally identified as E. squamula from Hippoglossina macrops Steindachner, 1876 (Bigeye flounder) (Pleuronectiformes: Paralichthyidae), caught off the coast of Chile by the Lund University Chile Expedition (1948 - 49), differ from E. squamula in the shapes of the accessory sclerites and are regarded as a new species, E. brinkmanni n. sp. E. aegyptiacus Amer, 1990 must be regarded as a species inquirenda. A key to the 7 valid species of Entobdella recognised by us is included. Entobdella pugetensis differs in the following ways from all other species of Entobdella: the parasite is found on gills (less commonly on skin) of Atheresthes stomias (Jordan \& Gilbert, 1880) (Arrowtooth flounder) (Pleuronectiformes: Pleuronectidae); the penis sac has a thick, possibly muscular, wall; the vagina is a relatively wide, short, straight tube with a conspicuous opening; no seminal receptacles have been observed; there are no papillae on the ventral surface of the haptor. We regard these distinctions as sufficient to erect a new genus, Branchobdella n. gen. to accommodate B. pugetensis n. comb. Assimilation of spermatophores in skin-parasitic Entobdella spp. and in the gill parasite B. pugetensis is discussed.

Key words: Platyhelminthes, Monogenea, Capsalidae, Entobdellinae, Entobdella brinkmanni n. sp., Entobdella hippoglossi sensu stricto, Entobdella stenolepis n. sp., Entobdella vanbenedeni n. sp., Branchobdella n. gen., Branchobdella pugetensis $\mathrm{n}$. comb., teleost flatfishes, sperm exchange

\section{Introduction}

Klassen et al. (1989) reviewed Entobdella Blainville in Lamarck, 1818 and drew attention to the fact that Entobdella spp. fell naturally into 2 groups, 1 parasitising teleost flatfishes and the other infecting elasmobranch flatfishes (rays). While appreciating the implication that Entobdella should be subdivided, Klassen et al. (1989) regarded this inappropriate at the time. The situation was reassessed by Kearn \& Whittington (2005) who took into account molecular analyses by Whittington et al. (2004) and the transfer of Entobdella corona Hargis, 1955 and E. guberleti Caballero \& Bravo-Hollis, 1962 to the newly proposed Listrocephalus Bullard, Payne \& Braswell, 2004 by Bullard et al. (2004). Kearn \& Whittington (2005) erected Neoentobdella 